\title{
SYNTHESIS AND CHARACTERIZATION OF SOME CARBON BASED NANOSTRUCTURES
}

\author{
Victor Ciupina, Univ. Ovidius Constanta (Romania); \\ Ion G. Morjan, Rodica Alexandrescu, Florian V. Dumitrache, National Institute for Lasers, Plasma and Radiation \\ Physics (Romania); \\ Gabriel Prodan, Univ. Ovidius Constanta (Romania); \\ Cristian Lungu, National Institute for Lasers, Plasma and Radiation Physics (Romania); \\ Rodica Vladoiu, Univ. Ovidius Constanta (Romania); \\ Ion Mustata, Vasile Zarovschi, National Institute for Lasers, Plasma and Radiation Physics (Romania); \\ John Sullivan, Sayah Saied, Aston Univ. (United Kingdom); \\ Eugeniu Vasile, S.C. Metav-Cercetare Dezvoltare S.A. (Romania); \\ Iuliana Oancea-Stanescu, Madalina Prodan, Dorina Manole, Aurelia Mandes, Virginia Dinca, Mirela Contulov, Univ. \\ Ovidius Constanta (Romania)
}

\begin{abstract}
The aim of present paper is to present the latest results on investigations of the carbon thin film deposited by Thermionic Vacuum Arc (TVA) method and laser pyrolysis. X-ray photoelectron spectroscopy (XPS) and X-ray generated Auger electron spectroscopy (XAES) were used to determine composition and sp2 to sp3 ratios in the outer layers of the film surfaces. The analyses were conducted in a Thermoelectron ESCALAB 250 electron spectrometer equipped with a hemispherical sector energy analyser. Monochromated Al K X-radiation was employed for the XPS examination, at source excitation energy of $15 \mathrm{KeV}$ and emission current of $20 \mathrm{~mA}$. Analyzer pass energy of $20 \mathrm{eV}$ with step size of $0.1 \mathrm{eV}$ and dwell time of $100 \mathrm{~ms}$ was used throughout.
\end{abstract}

Keywords: Carbon, TVA, laser pyrolysis, Transmission Electron Microscopy (TEM), XPS, XAES.

\section{INTRODUCTION}

Carbon based nanostructures are of considerable interest for application in nanotechnologies related fields such as medicine, electronics, catalysis, environment, glasses etc. Typical carbon based nanostructures methodologies involving different routes are presented: thin films vapor deposition procedures, iron-carbon nanostructures laser pyrolysis, catalyzed iron carbon nanoparticles, nanotubes, etc. The carbon thin films have been obtained by Thermionic Vacuum Arc method. The almost spherical carbon encapsulated iron nanoparticles with narrow size distribution were prepared via laser co-pyrolysis method in which the $\mathrm{CW} \mathrm{CO}_{2}$ laser beam irradiates a gas mixture containing iron pentacarbonyl (vapors) and ethylene/acetylene hydrocarbons. Specific flow geometries were used in order to synthesize iron particle first followed by stimulate hydrocarbon decomposition at iron surface. High-resolution transmission electron microscopy images reveal the core-shell feature of synthesized nanostructures with around $2 \mathrm{~nm}$ thick carbon layers and 3-7 $\mathrm{nm}$ diameters iron-based core dimensions. The mean diameter could be experimentally controlled. It was found a decreasing trend of particle size with the decreasing of pressure and total reactant gas flow. EDAX and Raman spectroscopy analysis confirm the simultaneous presence of carbon and iron [1]. The nanoparticles were seeded onto $\mathrm{Si}$ wafer and further used as substrates for laser induced CVD carbon nanotubes growth. Depending on laser power density, nanotubes or nanofibers are formed, in strong dependence with the location of iron based nanoparticles on Si substrates.

\section{METHOD AND SAMPLES}

The carbon thin films have been obtained by Thermionic Vacuum Arc (TVA) method. This deposition method consists from an externally heated cathode surrounded by a Wehnelt cylinder that concentrates the high voltage accelerated electrons on the anode material - carbon - in this case. Due to the high applied voltage, the continuously evaporated material from the anode ensures within the inter-electrodes space the formation of a steady state carbon vapors with enough density in order to ignite and to maintain a bright discharge. Because the discharge plasma is formed

Nanoengineering: Fabrication, Properties, Optics, and Devices VII, edited by Elizabeth A. Dobisz, Louay A. Eldada, Proc. of SPIE Vol. 7764, 776400 · (C) 2010 SPIE · CCC code: 0277-786X/10/\$18 · doi: 10.1117/12.859456 
only by electrons and carbon ions/neutrals, the films are deposited in high purity conditions [2]. The thin film is bombarded during its growth by the energetic carbon ions having energies up to $500 \mathrm{eV}$ [3].

In figure 1 it is presented the TVA experimental setup. The anode-cathode arrangement symmetry allows a perpendicular electron beam bombarding anode during deposition.

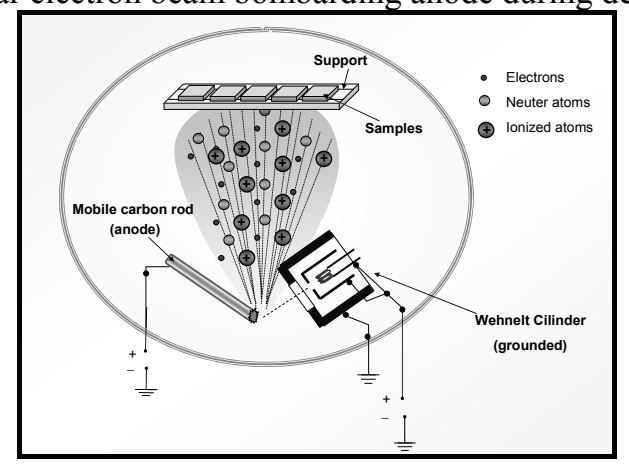

Figure1. Schematic view of the experimental arrangement for carbon film evaporation

The cathode filament was made by thoriated tungsten wire with $1.5 \mathrm{~mm}$ diameter, three times wound and heated by a current of 100A. During the arc running and carbon thin film deposition the anode was continuously rotating with 6rot/min, and also the cathode-anode distance was adjusted each time when the arc current was decreasing more than $10 \%$.

The almost spherical carbon encapsulated iron nanoparticles with narrow size distribution were prepared via laser co-pyrolysis method in which the $\mathrm{CW} \mathrm{CO}_{2}$ laser beam irradiates a gas mixture containing iron pentacarbonyl (vapors) and ethylene/acetylene hydrocarbons.

Due to the versatility of the laser pyrolysis method, we could develop several research directions in the field of nanomaterials: iron carbides, filamentary iron/iron oxide nanoparticles, nanocarbons, iron/carbon composites (core-shell structures), gamma iron oxide nanopowders, titanium-doped gamma iron oxide, carbon fibers and nanotubes, metalpolymer nanocomposites.

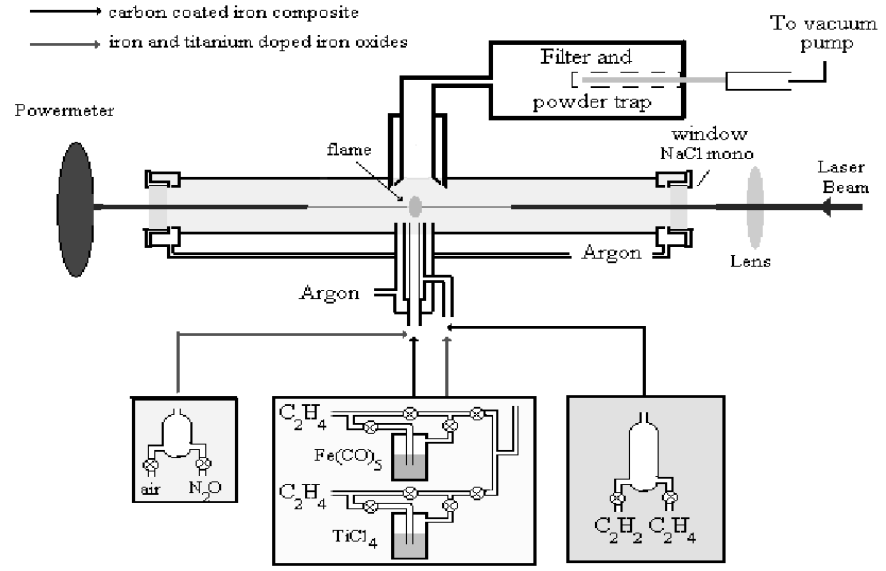

Figure 2. Experimental set-up for a single step experiment (CF)

Specific flow geometries were used in order to synthesize iron particle first followed by stimulate hydrocarbon decomposition at iron surface (figure2). Through the inner nozzle $\mathrm{C}_{2} \mathrm{H}_{4}$ was used as sensitizer for $\mathrm{Fe}(\mathrm{CO})_{5}$ fast decomposition and a hydrocarbon mixture $\left(\mathrm{C}_{2} \mathrm{H}_{2}+\mathrm{C}_{2} \mathrm{H}_{4}\right)$ was introduced through the middle tube.

\section{RESULTS AND DISCUSSIONS}

Hardness and Reduced Modulus were measured with a Micro Materials NanoTest 500 instrument using a NT Berkovich indenter (radius $\sim 150 \mathrm{~nm}$ ). The indentation depth was kept to $10-20 \%$ of the film thickness to minimize the influence from the substrate. The system has three different modules: indentation, for determining the hardness and 
elastic modulus of the deposited films; scratch and impact, mainly used to determine the adhesion of the films to substrates.

In figure 3, regarding to sample 1 , for the adhesion test, the critical loading was $20 \mathrm{mN}$ (thickness about $75 \mathrm{~nm}$ ). The adhesion is un-homogenous on the large scale. The adhesion test suggests that some parts of the coating are more adhesive than others, which is a measure of stress existent in the film.
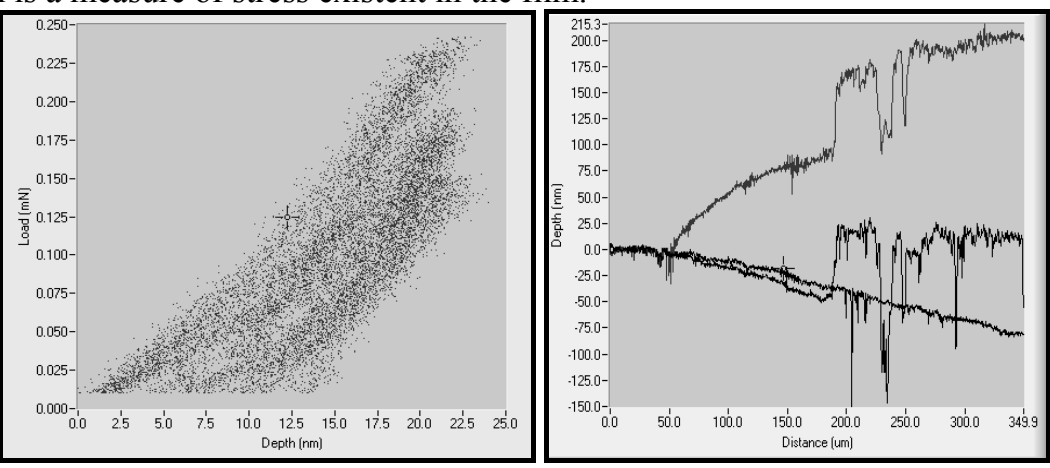

Figure 3. Hardness $=11.2 \pm 1.5 \mathrm{GPa}$, Reduced Modulus $=123.1 \pm 15.0 \mathrm{GPa}$

As it can be seen from figure 4, where the investigation were realized on sample 2, the critical loading was $17.5 \mathrm{mN}$ (thickness is about $80 \mathrm{~nm}$ ). The adhesion is homogenous on a large scale for this film.
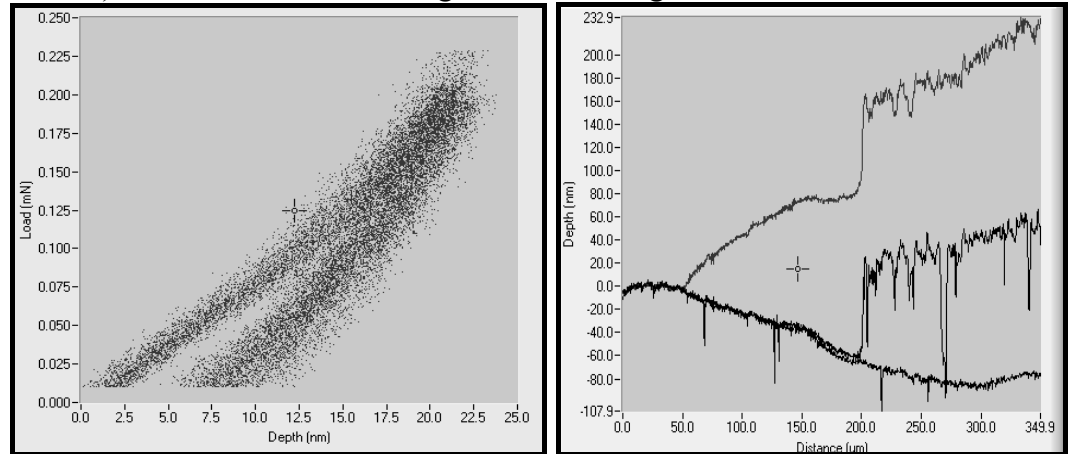

Figure 4. Hardness= $12.1 \pm 1.0 \mathrm{GPa}$, Reduced Modulus=133.7 $\pm 11.0 \mathrm{GPa}$

Multiple scratch tests were performed with the NanoTest 500 on each sample with a Cone 60 indenter, with a radius of $4 \mu \mathrm{m}$. the scratch length was $350 \mu \mathrm{m}$ and the maximum force applied during the tests was typically $40 \mathrm{mN}$. The critical load was defined as the load at which the indenter would penetrate though the coating onto the substrate.
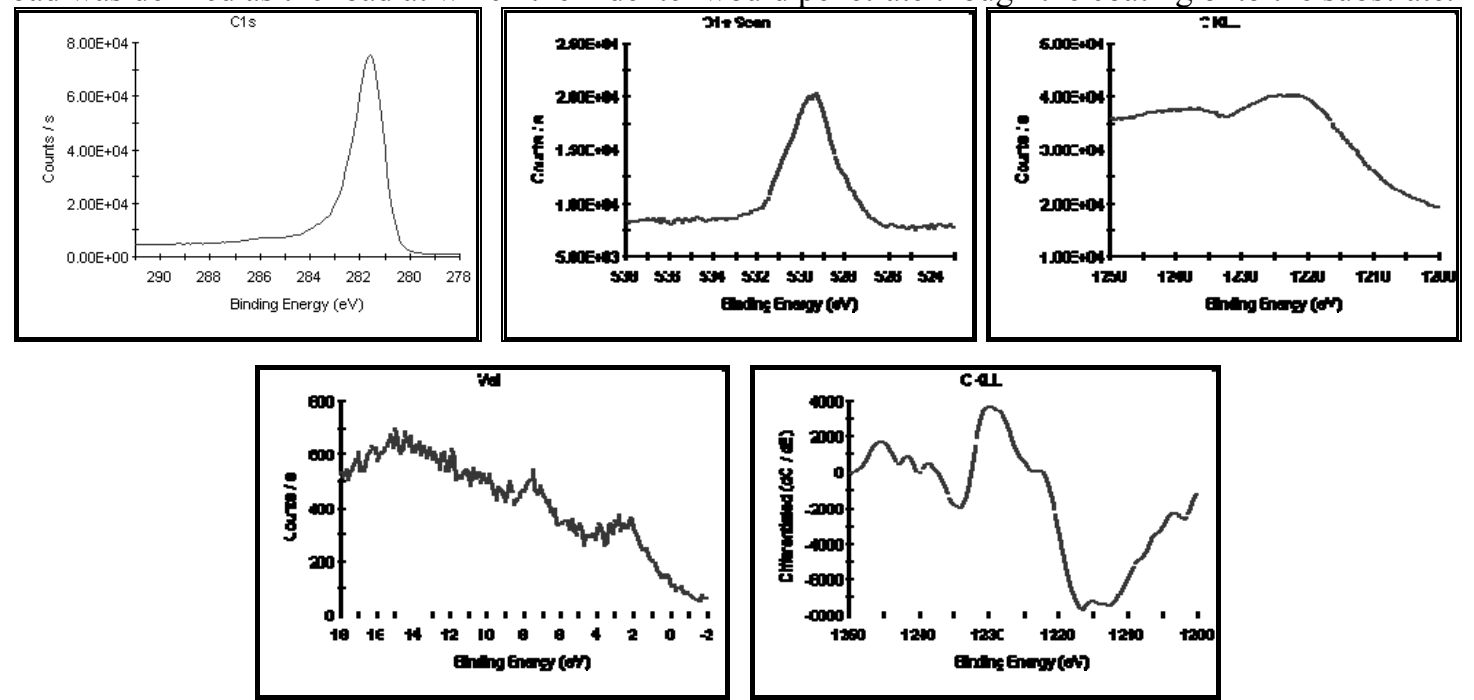

Figure 5. X-ray generated Auger electron spectroscopy (XAES) for carbon thin films obtained 
As it can be seen from figure 5, distance between positive and negative binding energy' shifts is represented by $\mathrm{D}$ value $=16.8$ equivalent to $69 \% \mathrm{sp}^{3}$ ratio.

Ar was detected at low relative atomic concentrations in all samples.

Electron Microscope CM120ST carried out Transmission Electron Microscopy (TEM), Selected Area Electron Diffraction (SAED), High Resolution Transmission Electron Microscopy (HRTEM) techniques to acquire images for morphological and structural investigation.

In figure 6 is exposed TEM image for thin carbon film obtained that presents diamond spherical grain.

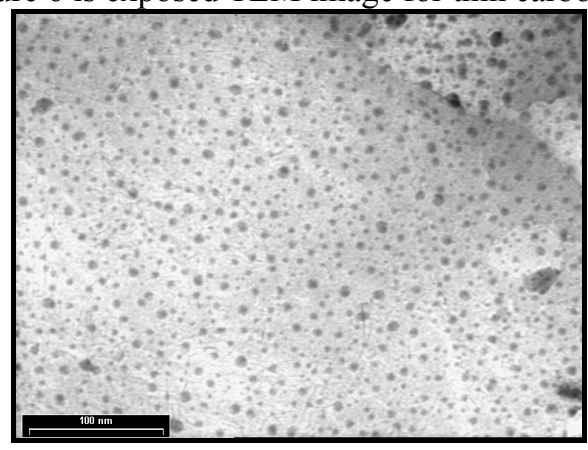

Figure 6. TEM image at $65000 \times$ working magnification $200 \mathrm{~nm}$ spot size

Bright Field Transmission Microscopy (BFTEM) image, 145kx working magnification, shaded correction and median filtered, and morphological close filters applied twice is presented in figure 7. Automated algorithm works on separated grains. Blue particles have no sharp edge and could be particles agglomerate. The value of particles was count and measured using Analysis software.

Morphology was determined from BF-TEM image. We calculate the mean diameters assuming a lognormal distribution of experimental distribution of experimental data (inserted image top-left in figure 7). The mean value of measured diameters from BFTEM images is 4.(1)nm.

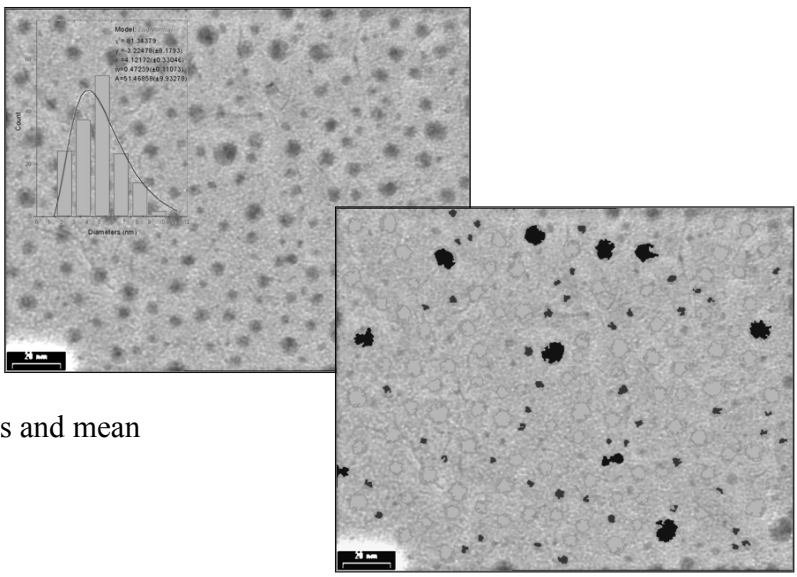

The selected area electron diffraction (SAED) pattern obtained for thin film, with $420 \mathrm{~mm}$ camera length and $200 \mathrm{~nm}$ spot size is shown in figure 8. Measured fringes could be indexed using cubic (diamond) structure of carbon, with lattice constant $a=0.356 \mathrm{~nm}$, space group Fd $\underline{3}$ m, ICSD 79-1467. 


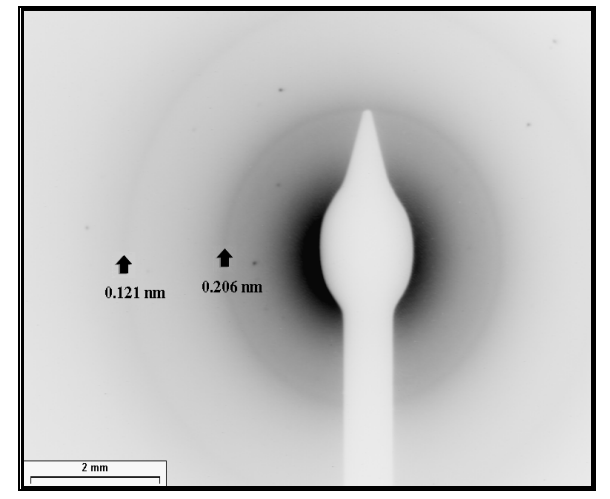

Figure 8. Selected Area Electron Diffraction pattern for thin film obtained
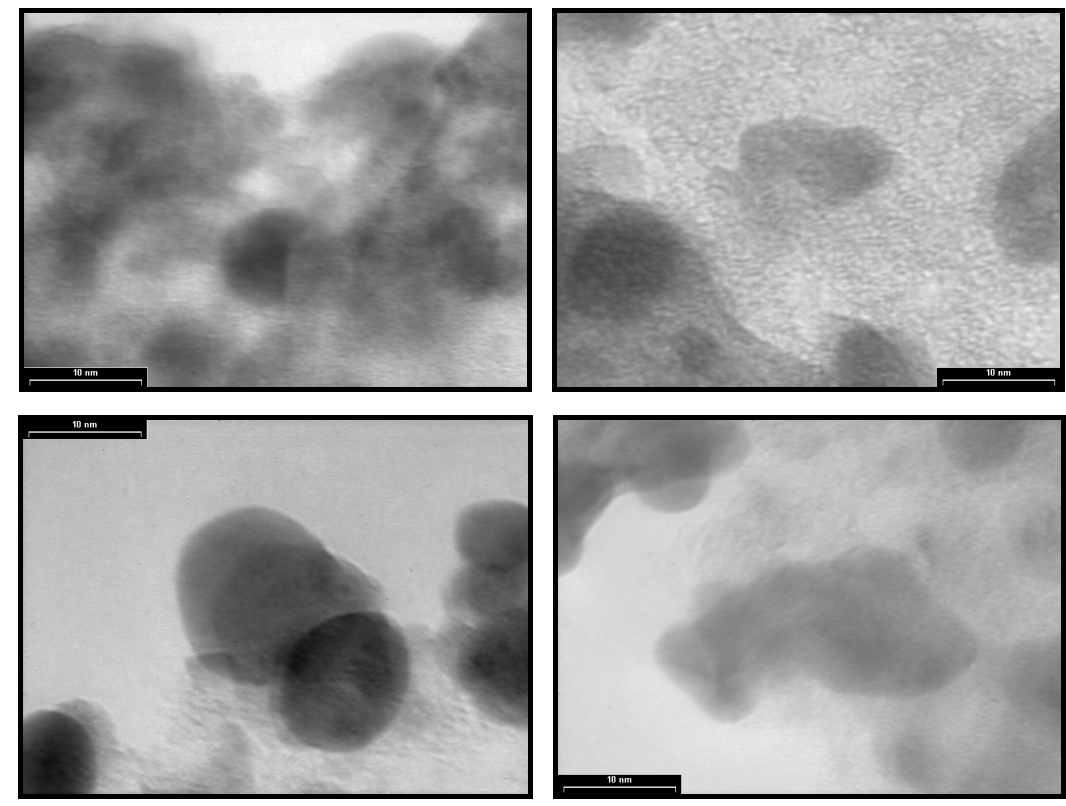

Figure 9. TEM images with carbon thin film and diamond nanoparticles

High Resolution Transmission Electron Microscopy images (figure9) on thin films show low range crystalline area with interference fringes corresponding to graphite structure. Inside of film from figure 9 top-left we can observe $5 \mathrm{~nm}$ or less diamond nanoparticles. The nanoparticles form agglomerate.

Thin films obtained by TVA method on silicon substrate has uniformity distribution of diamond grain, with mean diameter equal to 4.(1)nm.

Carbon encapsulated iron particles is a one-step procedure, where the carbon embedding degree depends on the control of experimental parameters and radiation geometry that generates narrow size distribution, particle mean diameter $4-6.5 \mathrm{~nm}$, as it is revealed from TEM analysis.

The experiment has been realized at a 650-700mbar pressure and 1100sccm Ar flow confinement. Experimental parameters are illustrated in Table1. 
Table1: Experimental parameters

\begin{tabular}{|c|c|c|c|}
\hline Run & $\begin{array}{c}\mathbf{C}_{2} \mathbf{H}_{\mathbf{4}} \text { carrier } \\
\text { for } \mathbf{F e}(\mathbf{C O})_{5} \\
\text { (sccm) }\end{array}$ & $\begin{array}{c}\mathbf{C}_{2} \mathbf{H}_{4} \text { in mixture } \\
\text { (sccm) }\end{array}$ & $\begin{array}{c}\mathbf{C}_{2} \mathbf{H}_{2} \text { in } \\
\text { mixture } \\
\text { (sccm) }\end{array}$ \\
\hline CF4 & 100 & 55 & 29 \\
\hline CF5 & 50 & 30 & 68 \\
\hline CF6 & 20 & 19 & 73 \\
\hline CF7 & 20 & 10 & 37 \\
\hline
\end{tabular}

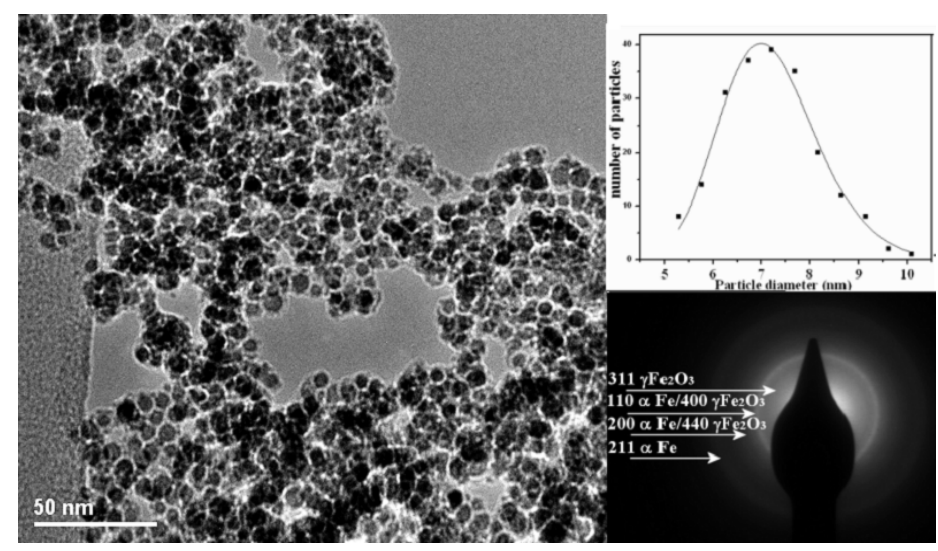

Figure 10. TEM image of the as-prepared sample, SAED pattern and particle size distribution (inserts)

Figure 10 contains TEM image of the as-prepared sample, SAED pattern and particle size distribution. Good quality dispersion of Fe nanoparticles embedded in a carbon matrix, almost each particle presents a core (dark contrast) surrounded by a shell. The particle distribution shows a mean size diameter of $7 \mathrm{~nm}$. Electron diffraction pattern reveals the presence of $\alpha$-Fe (110) and (211) (hkl) planes and possibly $\gamma-\mathrm{Fe}_{2} \mathrm{O}_{3}$ caused by the partial oxidation in the ambient.

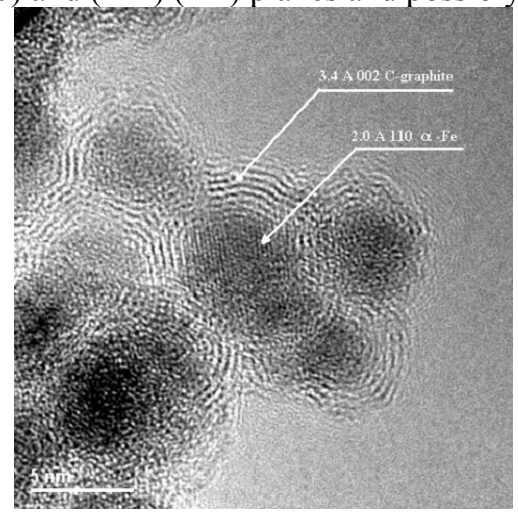

Figure 11. HRETM image of Fe-C nanocomposite residue

Particle diameter was found to be around $6 \mathrm{~nm}$ value, interplanar distances are ascribable to $\alpha$-Fe ad graphitic carbon, $0.2 \mathrm{~nm}$ and respectively $0.34 \mathrm{~nm}$ (figure 11 ). It also can be observed the surrounding well defined graphitic shell, with higher ordering between graphitic planes than in case of as-synthesized nanocomposite.

The TEM, HRTEM and SAED examination completed by Fast Fourier Transformation (FFT) of the laser irradiated $\mathrm{FeC} / \mathrm{Si}$ samples revealed the formation of numerous carbon nanotubes (figure 12-16). 


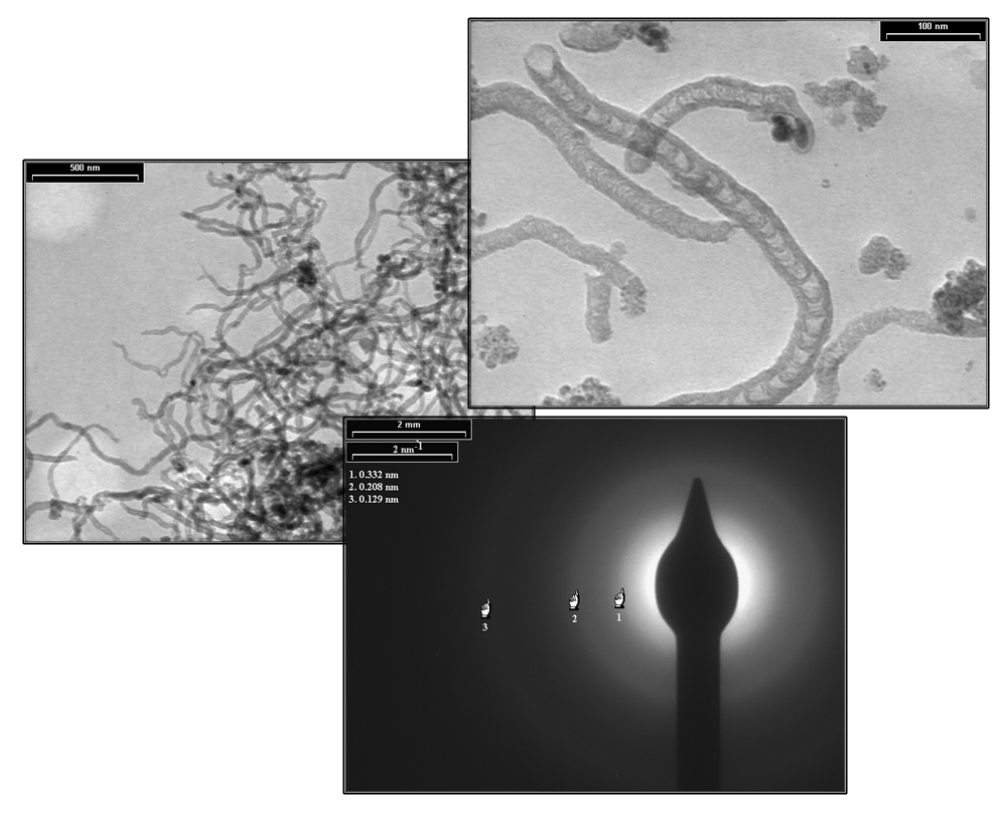

Figure 12. Nanotubes and nanofibers, TEM images and SAED pattern

Figure 13. TEM image of nanotubes and nanofibers (left). Detail view of nanotubes (right) with inset that present FFT transform of SAED that confirm (002)C plane reflection $(0.357 \mathrm{~nm})$
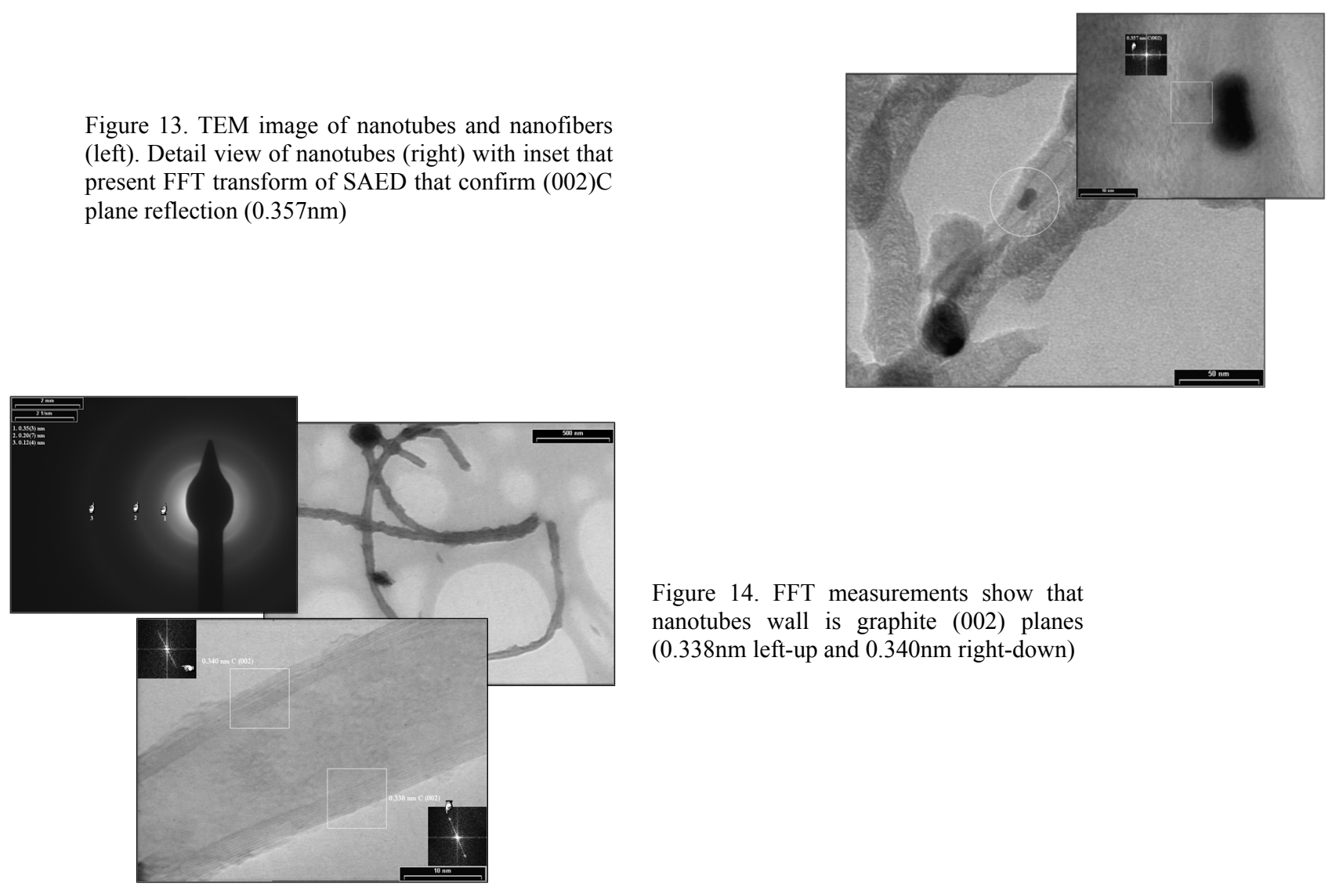

Figure 14. FFT measurements show that nanotubes wall is graphite (002) planes $(0.338 \mathrm{~nm}$ left-up and $0.340 \mathrm{~nm}$ right-down) 
Figure 15. Focused electron beam by carbon nanotube
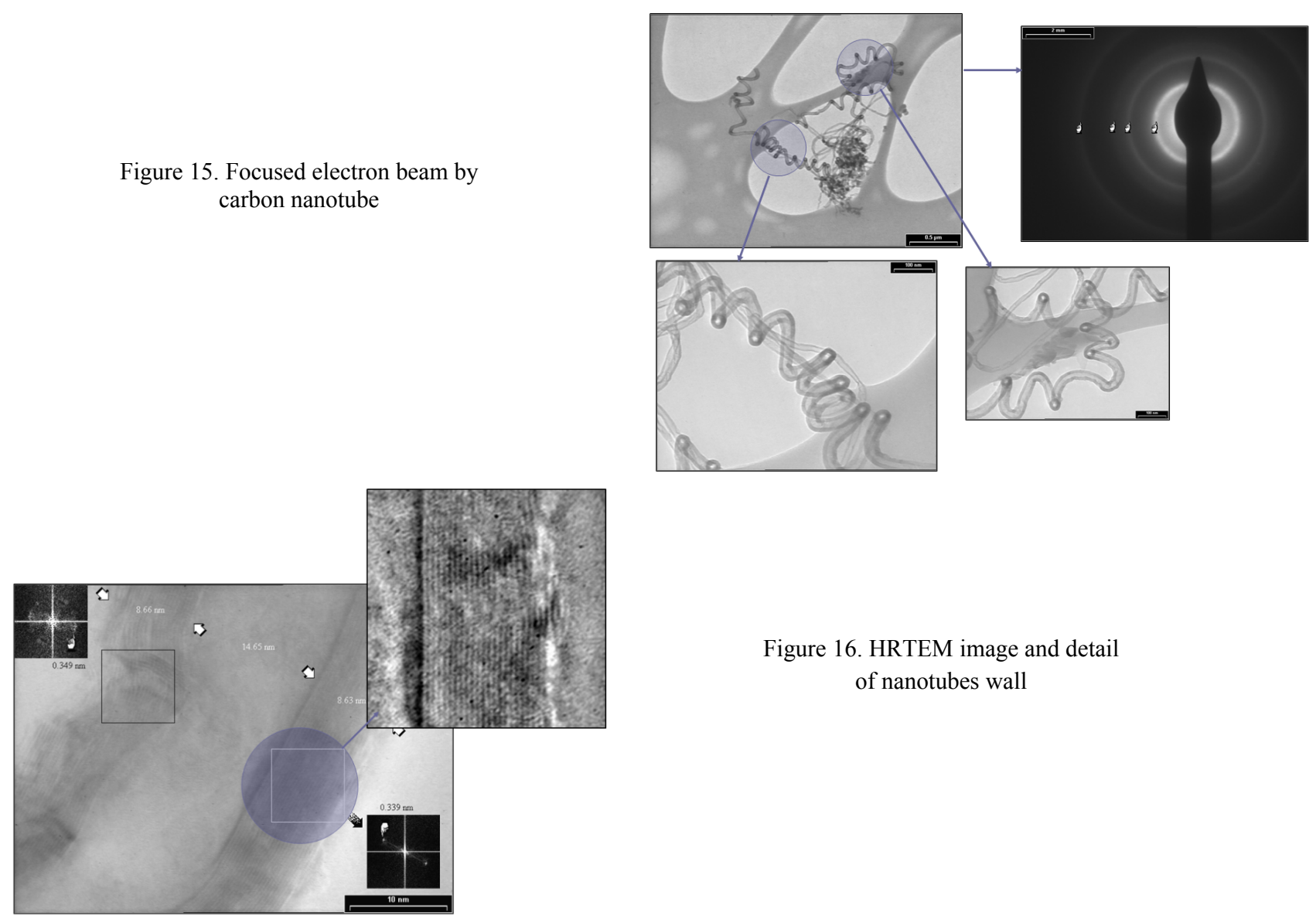

Figure 16. HRTEM image and detail of nanotubes wall

The laser pyrolysis method was employed in the gas phase for the synthesis of different nanopowders and composites. Soot containing different carbon nanoparticles were obtained by the laser pyrolysis of different hydrocarbons.

\section{CONCLUSIONS}

Preliminary results on carbon nanostructures characterization obtained through TVA method and laser pyrolysis have been reported. From TEM analyze it is revealed that thin films structure obtained through TVA procedure is corresponding to crystalline carbon, resulting possible applications in anticorrosive coatings for magnetic devices. Thin films obtained by TVA method on silicon substrate has uniformity distribution of diamond grain, with mean diameter equal to 4.(1)nm.

High-resolution transmission electron microscopy images reveal the core-shell feature of synthesized nanostructures with around $2 \mathrm{~nm}$ thick carbon layers and 3-7 nm diameters iron-based core dimensions. The mean diameter could be experimentally controlled. It was found a decreasing trend of particle size with the decreasing of pressure and total reactant gas flow.

Single-step experiment was leading to the synthesis of Fe-C nanocomposite formed of iron nanoparticles (4.5$6 \mathrm{~nm}$ mean diameters) with a low degree of agglomeration, which are covered by carbon layers.

The presented results demonstrate that thermionic vacuum arc and laser pyrolysis techniques may open new opportunities for the fabrication of nanomaterials and composites. 


\section{REFERENCES}

[1] V. Ciupina, F. Dumitrache, I. Morjan, R. Alexandrescu, G. Prodan, C. Fleaca, E. Popovici, I. Soare, L. Albu, R. Birjega, B. David, O. Schneeweiss, "Iron/iron carbides/carbon core-shell nanostructures synthesized by laser pyrolysis", Proc. SPIE 5924, 288-295 (2005)

[2] R.Vladoiu, V.Ciupina, C.Surdu-Bob, C.P.Lungu, J.Janik, J.D.Skalny, V.Bursikova, J.Bursik, G.Musa, "Properties of the carbon thin films deposited by thermionic vacuum arc", J.Optoel.Adv.Mater. 9(4), 862-866 (2007)

[3] G.Musa, I.Mustata, V.Ciupina, R.Vladoiu, G.Prodan, E.Vasile, H.Ehrich, "Diamond-like nanostructured carbon film deposition using thermionic vacuum arc", Diamond and Related Materials 13, 1398-1401 (2004)

[4] G. Musa, I. Mustata, V, Ciupina, R. Vladoiu, G. Prodan, C.P. Lungu, H. Ehrich, "Thermionic Vacuum Arc (TVA) Carbon thin film deposition", J.Optoel.Adv.Mat. 7(5), 2485-2487,(2005)

[5] I.M.Oancea Stanescu, V.Ciupina, G.Prodan, I.Morjan, I.Voicu, F.Dumitrache, E.Vasile, R. Trusca, M.Prodan, "Studies of carbon nanostructures by TEM procedures", J.Optoel.Adv.Mater. 10(12), 3257-3260(2008)

[6] Musa, G, Mustata, I.; Blideran, M.; Ciupina, V.; Vladoiu, R.; Prodan, G.; Vasile E.; Ehrich, H, "Thermionic vacuum arc-new technique for high purity carbon thin film deposition",Acta Physica Slovaca, 55(4), 417-421 (2005)

[7] Musa, G., Mustata, I., Blideran, M., Ciupina, V., Vladoiu, R., Prodan, G., Vasile E., "Nanostructured carbon thin films depfosition using Thermionic Vacuum Arc (TVA) technology", J.Optoel.Adv.Mater. 5(3), 667-673(2003)

[8] L. Gavrila-Florescu, I. Morjan, E. Popovici, I. Sandu, I. Voicu, I. Dinca, A. Stefan, C. Serghie, L. Dumitrache, C. Nistor, V. Stefan, S. Serban, D. Donescu, G. Prodan and V. Ciupina, "Laser-synthesized carbon nanopowders for nanoscale reinforced hybrid composites", Materials Science and Engineering: C 27(5-8), 1010-1014 (2007)

[9] F.Dumitrache, I.Morjan, R.Alexandrescu, R.E.Morjan, I.Voicu, I.Sandu, I.Soare, M.Ploscaru, C.Fleaca, V.Ciupina, G.Prodan, B.Rand, B.Brydson and A.Woodworld, "Nearly monodispersed carbon coated iron nanoparticles for catalytic growth of nanotubes/nanofibres", Diamond and Related Materials 13, 362-370 (2003)

[10] F. Dumitrache, I. Morjan, R. Alexandrescu , V. Ciupina, G. Prodan, I. Voicu, C. Fleaca, L. Albu, M. Savoiu, I. Sandu, E. Popovici, I. Soare, "Iron-Iron oxide core -shell nanoparticles synthesized by laser pyrolysis followed by superficial oxidation", Appl. Surf. Sci. 247, 25-31 (2005)

[11] J.Pola, Z.Bastl, V.Vorlieek, F.Dumitrache, R.Alexandrescu, I.Morjan, I.Sandu and V.Ciupina,"Laser-induced synthesis of iron-iron oxide/methylmethoxysilicone nanocomposite", Applied Organometal.Chem. 18(7), 337-342 (2004)

[12] I.Morjan, R.Alexandrescu, I.Soare, F.Dumitrache, I.Sandu, I.Voicu, A.Crunteanu, E.Vasile, V.Ciupina and S.Martelli,"Nanoscale powders of different iron oxide phases prepared by continuous laser irradiation of iron pentacarbonyl-containing gas precursors", Matter.Sci.Eng.C 23(1-2), 211-216 (2003) 